\title{
A polyphasic approach to the identification of aflatoxigenic and non-aflatoxigenic strains of Aspergillus Section Flavi isolated from Portuguese almonds
}

\author{
Paula Rodrigues ${ }^{\mathrm{a}, \mathrm{b}}$, Armando Venâncio ${ }^{\mathrm{a}, *}$, Zofia Kozakiewicz ${ }^{\mathrm{a}}$, Nelson Lima ${ }^{\mathrm{a}}$ \\ a IBB - Institute for Biotechnology and Bioengineering, Centre for Biological Engineering, Universidade do Minho, Campus de Gualtar, 4710-057 Braga, Portugal \\ b CIMO - Escola Superior Agrária de Bragança, Campus de Santa Apolónia, 5301-855 Bragança, Portugal
}

\section{A R T I C L E I N F O}

\section{Article history:}

Received 8 July 2008

Received in revised form 17 November 2008

Accepted 18 November 2008

\section{Keywords:}

Aspergillus

Section Flavi

Aflatoxins

Cyclopiazonic acid

\begin{abstract}
A B S T R A C T
A polyphasic approach consisting of morphological, chemical and molecular characterization was applied to 31 isolates of Aspergillus Section Flavi originating from Portuguese almonds, with the aim of characterizing and identifying aflatoxigenic and non-aflatoxigenic strains. On the basis of morphological characters (mainly colony color on Czapek-Dox agar and conidia morphology), we found two distinct groups among the population under study: 18 isolates (58\%) had dark-green colonies and rough conidia, and were classified as Aspergillus parasiticus; the remaining 13 isolates (42\%) had yellow-green colonies and smooth to finely rough globose conidia, and were classified as Aspergillus flavus. Chemical characterization involved the screening of the isolates for aflatoxins B (AFB) and G (AFG), and also for cyclopiazonic acid (CPA), by HPLC with fluorescence and UV detection, respectively. All A. parasiticus isolates were strong AFB and AFG producers, but no CPA production was detected, showing a consistent mycotoxigenic pattern. The A. flavus isolates showed to be more diversified, with $77 \%$ being atoxigenic, whereas $15 \%$ produced CPA and low levels of AFB and $8 \%$ produced the 3 groups of mycotoxins. Aflatoxin production was also screened on Coconut Agar Medium (CAM), and the results were consistent with the HPLC analysis. Sclerotia production showed no correlation to aflatoxigenicity.

Molecularly, two genes of the aflatoxin biosynthetic pathway, aflD (=nor1) and aflQ (=ord1=ordA) were tested for presence and expression (by PCR and RT-PCR, respectively). The presence of both genes did not correlate with aflatoxigenicity. aflD expression was not considered a good marker for differentiating aflatoxigenic from non-aflatoxigenic isolates, but aflQ showed a good correlation between expression and aflatoxin-production ability.
\end{abstract}

(c) 2008 Elsevier B.V. All rights reserved.

\section{Introduction}

Aflatoxins, potent carcinogenic toxins, are the most widely studied of all mycotoxins. Aflatoxins frequently contaminate agricultural commodities, thus causing serious health hazards to humans and animals, as well as great economic loss. Although aflatoxin-production ability has been detected in various species of the Aspergillus genus, inside and outside the Flavi group, Aspergillus flavus and Aspergillus parasiticus remain the most important and representative aflatoxin producers occurring naturally in food commodities (Cary and Ehrlich, 2006). Aspergillus nomius, which has also been reported as a strong aflatoxin producer (Kurtzman et al., 1987), has rarely been identified in survey studies from agricultural soils and commodities (Ehrlich et al., 2007; Fiebelman et al., 1998; Ito et al., 1998; Razzaghi-Abyaneh et al., 2006). This can be an artefact resulting from its strong resemblance with A. flavus (Kurtzman et al., 1987), thus leading to misidentification.

\footnotetext{
* Corresponding author.

E-mail address: avenan@deb.uminho.pt (A. Venâncio).
}

The identification of Aspergillus Section Flavi has been traditionally based on morphological and biochemical characterization. Conidial wall ornamentation is regarded as the primary morphological diagnostic character for separation of A. flavus and A. parasiticus. Conidia of A. flavus have relatively thin walls which are finely to moderately roughened. Their shape can vary from spherical to elliptical. Conidia of A. parasiticus are more spherical and noticeably echinulate or spinulose. When grown on Czapek-Dox (CZ) colonies of A. flavus are yellow-green and those of $A$. parasiticus have a distinctly darker green (Klich, 2002; Samson et al., 2004). A. nomius is morphologically similar to A. flavus in colour, but conidia are more roughened (Kurztman et al., 1987).

The mycotoxigenic profile (regarding aflatoxins B and G - AFB and AFG, respectively - and cyclopiazonic acid - CPA) of these strains has also been routinely used for identification purposes. In this matter, A. parasiticus tend to be more consistent than A. flavus (Wei and Jong, 1986), and therefore easier to classify. A. parasiticus strains are relatively uniform in their toxigenic abilities: they are usually strongly aflatoxigenic, producing both AFBs and AFGs, but not CPA. Non-aflatoxigenic strains have rarely been reported (Horn et al., 1996; Razzaghi-Abyaneh et al., 2006; Tran-Dinh et al., 1999; Vaamonde et al., 2003). On the other hand, A. flavus populations have been found to be extremely diverse in 
terms of morphology and toxigenicity, and have thus been divided into groups, depending on their toxigenic profile (Giorni et al., 2007; Razzaghi-Abyaneh et al., 2006; Vaamonde et al., 2003). Five groups have been proposed: (i) chemotype I for AFBs and CPA producers; (ii) chemotype II for AFBs, AFGs and CPA producers; (iii) chemotype III for AFBs producers; (iv) chemotype IV for CPA producers; and (v) chemotype $\mathrm{V}$ for non-producers (Vaamonde et al., 2003). The incidence of non-toxigenic strains of $A$. flavus has shown to be variable with geographic origin (Atehnkeng et al., 2008; Giorni et al., 2007; Razzaghi-Abyaneh et al., 2006) and substrate (Vaamonde et al., 2003).A. nomius exhibits a mycotoxigenic pattern similar to that of $A$. parasiticus (Kurztman et al., 1987).

Species identification based on morphological and biochemical characters is time-consuming and not always straight-forward, and molecular methods can be of help. But high genetic similarity between species of Aspergillus Section Flavi, as well as a high degree of intraspecific variability, has resulted in the inability to produce a molecular marker capable of consistently differentiating the various species. Some authors have reported the ability to differentiate Aspergillus Section Flavi species using molecular techniques (Ehrlich et al., 2004; Kumeda and Asao, 2001; Somashekar et al., 2004). These findings reflect the study of a limited number of strains (mostly lab strains), and they have not been tested with large numbers of field strains to confirm its utility as a molecular marker for species identification.

Molecular techniques have been widely applied also in the attempt of distinguishing aflatoxinogenic and non-aflatoxigenic strains of A. flavus and A. parasiticus, through the correlation of presence/absence of one or several genes involved in the aflatoxin biosynthetic pathway with the ability/inability to produce aflatoxins. Some groups have been able to distinguish these species from other food-borne fungi (Criseo et al., 2001; Färber et al., 1997; Geisen, 1996; Shapira et al., 1996), but none was capable of distinguishing aflatoxigenic from non-aflatoxigenic strains.

More recently, aflatoxin production and aflatoxigenic strains differentiation are being assessed by monitoring the expression of aflatoxin genes using the reverse transcription polymerase chain reaction (RT-PCR) and real-time PCR methodologies. Such systems have been applied to monitor aflatoxin production and aflatoxin gene expression based on various regulatory and structural aflatoxin pathway genes in A. parasiticus and/or A. flavus (Degola et al., 2007; Mayer et al., 2003; Scherm et al., 2005; Sweeney et al., 2000), and were found to be very rapid and sensitive. But AF biosynthesis is based on a highly complex pathway. It requires at least 25 structural and 2 regulatory genes (Yu et al., 2004a), with possible alternative pathways (Detroy et al., 1973). It is thus not surprising that the protocols that can fully differentiate between AF producers and non-producers have not yet been successfully established. Furthermore, one has to be aware that some genes are not exclusive of the aflatoxin biosynthetic pathway, which could create false-positives from sterigmatocystin producing fungi (Paterson, 2006). An example being Aspergillus nidulans, which harbors the complete aflatoxin biosynthesis pathway except for the final step that converts sterigmatocystin to aflatoxin (Brown et al., 1996).

The identification methods previously described have not been applied in a concerted way. Also, they were mostly tested with lab strains. The aim of this study was to characterize 31 field strains of
Aspergillus Section Flavi originating from Portuguese almonds, based on a polyphasic approach involving morphological, chemical and molecular patterns. This is the first report of characterization of Aspergillus Flavi isolated from a Portuguese agricultural commodity.

\section{Materials and methods}

\subsection{Fungal isolates and culture conditions}

Thirty-one isolates of Aspergillus Section Flavi, isolated from almonds from the Northeast of Portugal (region of Trás-os-Montes), were used in this study as field isolates, designated with the code yyAAspnn, where yy means the year, A refers to the commodity (almond), Asp refers to the genus Aspergillus and, $\mathrm{nn}$ is the isolate number. Type strains MUM92.01 (=NRRL6412, non-aflatoxigenic) and MUM92.02 (=NRRL3386, aflatoxigenic) from the collection of Micoteca of University of Minho (Portugal) were used as reference strains for $A$. flavus and $A$. parasiticus, respectively. Two A. flavus strains isolated from other commodities were included in the study: strain 01UAs55 (isolated from wine grapes, Portugal), and strain 05BrUAs01 (isolated from wine grapes, Brazil). These strains, although not being lab strains, were used as negative controls in molecular studies, since they were previously determined to be negative for the genes under study.

All isolates were maintained in $20 \%$ glycerol at $-20{ }^{\circ} \mathrm{C}$ and grown on Malt Extract Agar (MEA: Malt $20 \mathrm{~g} / \mathrm{L}$, Glucose $20 \mathrm{~g} / \mathrm{L}$, Peptone $1 \mathrm{~g} / \mathrm{L}$, Agar $20 \mathrm{~g} / \mathrm{L}$ ) in the dark for 7 days at $25^{\circ} \mathrm{C}$ whenever needed for further studies.

\subsection{Morphological characterization}

For each isolate, a loop full of spores was suspended in $500 \mu \mathrm{L}$ of $0.2 \%$ agar, and this suspension was used for three-point inoculations on $9 \mathrm{~cm}$ diameter Petri dishes containing $20 \mathrm{~mL}$ of MEA and CZ (Sucrose $30 \mathrm{~g} / \mathrm{L}$, $\mathrm{K}_{2} \mathrm{HPO}_{4} 1 \mathrm{~g} / \mathrm{L}, \mathrm{NaNO}_{3} 2 \mathrm{~g} / \mathrm{L}, \mathrm{KCl} 0.5 \mathrm{~g} / \mathrm{L}, \mathrm{MgSO}_{4} \cdot 7 \mathrm{H}_{2} \mathrm{O} 0.5 \mathrm{~g} / \mathrm{L}, \mathrm{FeSO}_{4} \cdot 7 \mathrm{H}_{2} \mathrm{O}$ $0.01 \mathrm{~g} / \mathrm{L}, \mathrm{ZnSO}_{4} \cdot 7 \mathrm{H}_{2} \mathrm{O} 0.01 \mathrm{~g} / \mathrm{L}, \mathrm{CuSO}_{4} \cdot 5 \mathrm{H}_{2} \mathrm{O} 0.005 \mathrm{~g} / \mathrm{L}$, Agar $\left.20 \mathrm{~g} / \mathrm{L}\right)$. Cultures were incubated for 7 days, in the dark, at $25{ }^{\circ} \mathrm{C}$ and then analysed for colony colour, presence and size of sclerotia, head seriation and conidia morphology. Colony colour on CZ was confirmed after 14 days of incubation. Identification followed the taxonomic keys and guides available for the Aspergillus genus (Klich, 2002; Samson et al., 2004). All isolates were cultured on A. flavus and parasiticus Agar (AFPA; Oxoid, Basingstoke, United Kingdom) for 3 to 5 days at $25^{\circ} \mathrm{C}$, in the dark, to confirm group identification by colony reverse colour. Isolates were also cultured on $\mathrm{CZ}$ at $42{ }^{\circ} \mathrm{C}$, and colony diameter was measured after 7 days of incubation (Kurtzman et al., 1987), to confirm identification. Species identification followed characterization summarized in Table 1.

\subsection{Mycotoxigenic ability of the isolates}

\subsubsection{Fluorescence on Coconut Agar Medium}

For a preliminary screening of aflatoxin production, strains were inoculated at a central point on a $6 \mathrm{~cm}$ diameter Petri dish containing $10 \mathrm{~mL}$ of Coconut Agar Medium (Davies et al., 1987) and incubated for 7 days in the dark at $25{ }^{\circ} \mathrm{C}$. Cultures were observed for fluorescence under long-wave UV light (365 nm) after 3, 5 and 7 days.

Table 1

A compilation of distinguishing characters of Aspergillus Section Flavi (from: Kurtzman et al., 1987; Klich, 2002; Samson et al., 2004)

\begin{tabular}{|c|c|c|c|c|c|c|c|c|}
\hline Species & Seriation $^{\mathrm{a}}$ & Conidia morphology & Colony color & AFPA & Colony diameter $(\mathrm{cm}), \mathrm{CZ}, 42{ }^{\circ} \mathrm{C}$ & $\mathrm{AFBs}^{\mathrm{b}}$ & $A F G s^{b}$ & $\mathrm{CPA}^{\mathrm{b}}$ \\
\hline A. flavus & $\mathrm{b}$ or $\mathrm{b} / \mathrm{u}$ & Smooth & Yellow-green & Orange & $2.4-3.6$ & + & - & + \\
\hline A. parasiticus & $\mathrm{u}$ or $\mathrm{u} / \mathrm{b}$ & Rough & Dark-green & Orange & $1.8-3.3$ & + & + & - \\
\hline A. nomius & $\mathrm{u}$ or $\mathrm{u} / \mathrm{b}$ & Rough & Yellow-green to olive-green & Orange & $0-1.5$ & + & + & - \\
\hline A. oryzae & variable & Rough & Brown & Cream & $1.8-3.2$ & - & - & $(+)$ \\
\hline A. sojae & - & Smooth & Pale brown & Orange & $1.5-2.7$ & - & - & - \\
\hline A. tamarii & - & Rough & Dark-brown & Brown & $0.2-1.0$ & - & - & + \\
\hline
\end{tabular}

\footnotetext{
${ }^{a}$ u: uniseriate; b: biseriate; u/b: predominantly uniseriate; b/u: predominantly biseriate.
}

b +: presence; -: absence; (+) variable. 


\subsubsection{HPLC analysis}

2.3.2.1. Aflatoxins detection. All strains were tested for aflatoxin production in aflatoxin-inducing Yeast Extract Sucrose (YES) medium (Yeast Extract 20 g/L, Sucrose 150 g/L, Agar 15 g/L). Strains MUM92.01, MUM92.02, 07AAsp05, 08AAsp42 and 08AAsp68 were also tested for aflatoxin production in the non-inducing Yeast Extract Peptone (YEP) medium (Yeast Extract $20 \mathrm{~g} / \mathrm{L}$, Peptone $150 \mathrm{~g} / \mathrm{L}$, Agar $15 \mathrm{~g} / \mathrm{L}$ ). Strains were inoculated on $6 \mathrm{~cm}$ diameter plates and incubated at $25-27^{\circ} \mathrm{C}$ for 7 days, in the dark. Then the methodology of Bragulat et al. (2001) was employed: briefly, 3 agar plugs were removed from one colony, and placed into a $4 \mathrm{~mL}$ vial, where $1 \mathrm{~mL}$ of methanol was added. After $60 \mathrm{~min}$, the extract was filtered by $0.45 \mu \mathrm{m}$ filters and analysed by HPLC.

Samples were analysed using a HPLC equipped with a Jasco FP-920 fluorescence detector (365 nm excitation wavelength; $435 \mathrm{~nm}$ emission wavelength), using a photochemical post-column derivatization reactor (PHRED unit - Aura Industries, USA). Chromatographic separations were performed on a reverse phase C18 column (Waters Spherisorb ODS2, $4.6 \mathrm{~mm} \times 250 \mathrm{~mm}, 5 \mu \mathrm{m})$, fitted with a precolumn with the same stationary phase. The mobile phase used was pumped at $1.0 \mathrm{~mL} / \mathrm{min}$ and consisted of an isocratic programme as follows: water:acetonitrile: methanol $(3: 1: 1, v / v)$. The injection volume was $100 \mu \mathrm{L}$.

Aflatoxins standard was supplied by Biopure (Austria). A mix of aflatoxins, containing $2 \mu \mathrm{g} / \mathrm{mL}$ each of AFB1 and AFG1, and $0.5 \mu \mathrm{g} / \mathrm{mL}$ each of AFB2 and AFG2 was used. Samples were taken as positive for each of the toxins when yielding a peak at a retention time similar to each standard, with a height five times higher than the baseline noise.

2.3.2.2. Cyclopiazonic acid detection. The strains were tested for cyclopiazonic acid in Czapek Yeast Autolysate medium (CYA: Sucrose $30 \mathrm{~g} / \mathrm{L}$, Powdered Yeast Extract $5 \mathrm{~g} / \mathrm{L}, \mathrm{K}_{2} \mathrm{HPO}_{4} 1 \mathrm{~g} / \mathrm{L}, \mathrm{NaNO}_{3} 2 \mathrm{~g} / \mathrm{L}, \mathrm{KCl}$ $0.5 \mathrm{~g} / \mathrm{L}, \mathrm{MgSO}_{4} \cdot 7 \mathrm{H}_{2} \mathrm{O} 0.5 \mathrm{~g} / \mathrm{L}, \mathrm{FeSO}_{4} \cdot 7 \mathrm{H}_{2} \mathrm{O} 0.01 \mathrm{~g} / \mathrm{L}, \mathrm{ZnSO}_{4} \cdot 7 \mathrm{H}_{2} \mathrm{O} 0.01 \mathrm{~g} / \mathrm{L}$, $\mathrm{CuSO}_{4} \cdot 5 \mathrm{H}_{2} \mathrm{O} 0.005 \mathrm{~g} / \mathrm{L}$, Agar $20 \mathrm{~g} / \mathrm{L}$ ). All strains were inoculated on $6 \mathrm{~cm}$ diameter plates and incubated at $25^{\circ} \mathrm{C}$ for 14 days, in the dark (Gqaleni et al., 1997). Then the methodology of Bragulat et al. (2001) was employed, as already described for aflatoxin analysis.

Samples were analysed using a HPLC equipped with a Varian 2050 UV detector (285 nm). Chromatographic separations were performed on a EuroSpher $100 \mathrm{NH} 2$ column (Knauer, $4.6 \mathrm{~mm} \times 250 \mathrm{~mm}, 5 \mu \mathrm{m}$ ), fitted with a precolumn with the same stationary phase. The mobile phase used was pumped at $1.0 \mathrm{~mL} / \mathrm{min}$ and consisted of an isocratic programme as follows: acetonitrile:50 mM ammonium acetate (3:1,v/v), pH 5. The injection volume was $100 \mu \mathrm{L}$.

Cyclopiazonic acid standard was supplied by Sigma (St. Louis, MO, USA). Samples were taken as positive when yielding a peak at a retention time similar to the CPA standard, with a height five times higher than the baseline noise.

\subsection{Molecular characterization}

2.4.1. Detection of aflatoxin genes aflD (=nor1) and aflQ (=ordA=ord1)

The nomenclature of the genes will follow that proposed by $\mathrm{Yu}$ et al. (2004b).
2.4.1.1. DNA extraction. A loop full of spores was transferred from a 7 day old culture into a $15 \mathrm{~mL}$ tube containing $1.5 \mathrm{~mL}$ of lysis buffer (200 mM Tris-HCl pH 8.5; 250 mL NaCl; 25 mM EDTA; 0.5\% [w/v] SDS) and approximately $1 \mathrm{~g}$ of sterile acid-washed 0.4 - to 0.6 -mm-diameter glass beads (Sigma, St. Louis, MO, USA), and vortexed for $5 \mathrm{~min}$ at maximum speed. Polysaccharides and proteins were precipitated by adding $750 \mu \mathrm{L}$ of cold $3 \mathrm{M}$ sodium acetate, $\mathrm{pH}$ 5.5. This mixture was gently mixed by inversion, placed at $-20^{\circ} \mathrm{C}$ for $10 \mathrm{~min}$ and centrifuged twice at $14000 \mathrm{~g}$ for $10 \mathrm{~min}\left(4^{\circ} \mathrm{C}\right)$. Clean supernatant was then transferred to a new tube and precipitated with one volume of cold isopropanol $\left(-20^{\circ} \mathrm{C}\right)$. This solution was gently mixed by inversion for a few minutes, incubated at $-20^{\circ} \mathrm{C}$ for $1 \mathrm{~h}$ and centrifuged at $14000 \mathrm{~g}$ for $10 \mathrm{~min}\left(4^{\circ} \mathrm{C}\right)$. DNA pellet was washed twice with $1.0 \mathrm{~mL}$ of cold $70 \%$ ethanol, centrifuged at $6000 \mathrm{~g}$ for $5 \mathrm{~min}\left(4^{\circ} \mathrm{C}\right)$ and air dried. DNA was resuspended in 100 to $200 \mu \mathrm{L}$ of ultra-pure water, depending on the yield, and stored at $-20^{\circ} \mathrm{C}$.

\subsubsection{PCR amplification}

PCR amplifications were performed on $25 \mu \mathrm{L}$ of a reaction mixture containing $\mathrm{MgCl}_{2}$-free reaction buffer, $1.5 \mathrm{mM} \mathrm{MgCl}, 1.25 \mathrm{U}$ of Taq polymerase, $200 \mu \mathrm{M}$ of each dNTP, $0.2 \mu \mathrm{M}$ of each primer (see Table 2 for list of primers) and $1 \mathrm{ng} / \mu \mathrm{L}$ of template DNA.

PCR was carried out as follows: 1) 1 step at $94{ }^{\circ} \mathrm{C}$ for $3 \mathrm{~min} ; 2$ ) 30 cycles of the following three steps: $1 \mathrm{~min}$ at $94{ }^{\circ} \mathrm{C}, 1 \mathrm{~min}$ at $55^{\circ} \mathrm{C}$, $1 \mathrm{~min} 72{ }^{\circ} \mathrm{C}$; and 3) one final $10 \mathrm{~min}$ step at $72^{\circ} \mathrm{C}$.

Genes aflD and aflQ were tested for all strains, using the primer pairs nor1-F/nor1-R and ord1-gF/ord1-gR, respectively. aflD primers were specifically designed in this study; aflQ primers were selected from previous studies.

The housekeeping gene tub1 coding for $\beta$-tubulin (primer pair tub1-F/tub1-R) was used as internal amplification control (IAC).

\subsubsection{Analysis of aflD and aflQ expression}

2.4.3.1. Total RNA extraction. For gene expression experiments, a loop full of spores was inoculated into a $50 \mathrm{~mL}$ tube containing $25 \mathrm{~mL}$ of YES broth and incubated for 4 days at $25{ }^{\circ} \mathrm{C}$, in the dark with agitation. Strains MUM92.01, MUM92.02, 07AAsp05, 08AAsp42 and 08AAsp68 were also tested in the non-inducing medium YEP broth. Approximately $200 \mathrm{mg}$ of mycelia were then recovered with a sterile spatula, dried in absorbent paper and ground with liquid nitrogen in a sterile, cold mortar and pestle. Total RNA was extracted with the RNeasy Plant Mini Kit (Qiagen, Hilden, Germany), including a step of genomic DNA digestion with RNase-free DNase set (Qiagen, Hilden, Germany), according to manufacturer's instructions. RNAs were aliquoted and stored at $-80^{\circ} \mathrm{C}$.

2.4.3.2. Reverse transcriptase PCR. RT-PCR was performed in $20 \mu \mathrm{L}$ reaction of $8 \mu \mathrm{L}$ of One-Step RT-PCR Pre-Mix kit (INTRON Biotechnology, Gyeonggi-do, South-Korea), $0.2 \mu \mathrm{M}$ of each primer (Table 2 ) and $1 \mu \mathrm{g}$ of template RNA. Reverse Transcription was obtained at $45^{\circ} \mathrm{C}$ for $30 \mathrm{~min}$. PCR parameters followed those reported by Degola et al. (2007): 4 min at $94^{\circ} \mathrm{C} ; 60$ s at $94^{\circ} \mathrm{C}, 1 \mathrm{~min}$ at $60^{\circ} \mathrm{C}$ and 1 min at $72^{\circ} \mathrm{C}$ for 5 cycles; 1 min at

Table 2

Details of the target genes, primer sequences and expected product length in base pairs (bp) for PCR and RT-PCR

\begin{tabular}{|c|c|c|c|c|c|}
\hline Primer pair & Gene & Primer sequence $\left(5^{\prime} \rightarrow 3^{\prime}\right)$ & PCR product legth (bp) & RT-PCR product size (bp) & Reference \\
\hline Tub1-F & tub1 & GCT TTC TGG CAA ACC ATC TC & 1406 & 1198 & Scherm et al. (2005) \\
\hline Tub1-R & & GGT CGT TCA TGT TGC TCT CA & & & Scherm et al. (2005) \\
\hline Nor1-F & aflD & ACC GCT ACG CCG GCA CTC TCG GCA C & 400 & 400 & This study \\
\hline Nor1-R & & GTT GGC CGC CAG CTT CGA CAC TCC G & & & This study \\
\hline Ord1-gF & aflQ & TTA AGG CAG CGG AAT ACA AG & & & Sweeney et al. (2000) \\
\hline Ord1-gR & & GAC GCC CAA AGC CGA ACA CAA A & 719 & 599 & Sweeney et al. (2000) \\
\hline Ord1-cR & & GAATATCTGGACGTTTACCC & - & 487 & Degola et al. (2007) \\
\hline
\end{tabular}


$94^{\circ} \mathrm{C}, 1 \mathrm{~min}$ at $55^{\circ} \mathrm{C}$ and $1 \mathrm{~min}$ at $72^{\circ} \mathrm{C}$ for 30 cycles; and a final extension at $72{ }^{\circ} \mathrm{C}$ for $6 \mathrm{~min}$. To check for the presence of genomic DNA contamination in the total RNA samples, PCR was carried out as described above, using the same set of primers and $1 \mu \mathrm{g}$ of total RNA as template. The primers used for gene expression detection included those previously mentioned plus ord1-cR, specific for RNA.

The housekeeping gene tub1 was used as IAC.

\section{Results}

\subsection{Morphological analysis}

Morphological characterization of the isolates is summarized in Table 3. On the basis of morphological characters (mainly colony color on $\mathrm{CZ}$ and conidia morphology), we found two distinct groups among the population under study: isolates with dark-green colonies and rough conidia, which were classified as A. parasiticus (18 isolates, 58\%), and isolates with yellow-green colonies and smooth to finely rough globose conidia, classified as A. flavus (12 isolates, 42\%). The isolate 07AAsp37 showed a somewhat distinct colony colour, more olivacious than those of the other A. flavus isolates, and moderately rough conidia.

Three of the 18 isolates classified as A. parasiticus (namely, 08AAsp34, 08AAsp36 and 08AAsp66) had limited growth on CZ at
$42{ }^{\circ} \mathrm{C}$, which could lead to the classification as A. nomius. But we were not able to find any other distinguishing features from other $A$. parasiticus isolates to support this reassignment. These isolates are all sclerotia producers. Kurtzman et al. (1987) characterize A. nomius sclerotia as vertically elongated, with indeterminate growth. This was not the case for these isolates, which showed globose to slightly elongate sclerotia typical of $A$. flavus and A. parasiticus.

All isolates were confirmed as Aspergillus Section Flavi by a bright orange colour of the colony reverse on AFPA (data not shown). None of the isolates showed a cream or brown colour on AFPA (corresponding to A. oryzae (Ahlburg) Cohn and A. tamarii Kita, respectively).

From the 31 isolates, 15 (48\%) were able to produce dark oblong sclerotia bigger than $400 \mu \mathrm{m}$ long in average, after 7 to 10 days of incubation on $\mathrm{CZ}$ (Table 3). Isolates of both A. flavus (8 isolates) and $A$. parasiticus ( 7 isolates) were sclerotia producers.

\subsection{Chemical analysis}

Analysis of aflatoxin production by fluorescence in CAM showed a good correlation with the HPLC results (Table 3). We found that all strains producing a strong signal for AFBs on the HPLC chromatogram showed a marked blue fluorescence pattern on CAM after 3 days of incubation, whereas those producing a weak signal by HPLC showed a

Table 3

Morphological and chemical characterization of isolates of Aspergillus Section Flavi

\begin{tabular}{|c|c|c|c|c|c|c|c|c|c|c|c|c|}
\hline \multirow[t]{2}{*}{ Isolate code } & \multicolumn{5}{|l|}{ Morphology } & \multicolumn{6}{|l|}{ Toxigenicity } & \multirow[t]{2}{*}{ Classification } \\
\hline & Sclerotia size $(\mu \mathrm{m})^{\mathrm{a}}$ & Seriation $^{b}$ & Conidia $^{c}$ & $\begin{array}{l}\text { Colony } \\
\text { color }^{\mathrm{d}}\end{array}$ & $\begin{array}{l}\text { Colony diameter } \\
\text { at } 42{ }^{\circ} \mathrm{C}^{\mathrm{e}}\end{array}$ & $\begin{array}{l}\text { Fluorescence } \\
\text { on CAM }\end{array}$ & $\mathrm{AF} \mathrm{B} 1^{\mathrm{f}}$ & $\mathrm{AF} \mathrm{B}^{\mathrm{f}}$ & $\mathrm{AF} \mathrm{G1} 1^{\mathrm{f}}$ & $\mathrm{AF} \mathrm{G2}{ }^{\mathrm{f}}$ & $\overline{\mathrm{CPA}^{\mathrm{t}}}$ & \\
\hline 07AAsp05 & 860 & $\mathrm{~b} / \mathrm{u}$ & $r$ & $\mathrm{~d}$ & 1.4 & Blue & + & $+1-$ & + & + & - & A. parasiticus \\
\hline 07AAsp37 & - & $\mathrm{u} / \mathrm{b}$ & $\mathrm{fr}$ & $y / d$ & 1.4 & Violet & + & $+1-$ & + & $+1-$ & + & A. flavus \\
\hline 07AAsp43 & - & $\mathrm{u} / \mathrm{b}$ & $r$ & d & 1.5 & Blue & + & $+1-$ & + & + & - & A. parasiticus \\
\hline 08AAsp34 & 600 & $\mathrm{u}$ & $r$ & $d$ & 0.8 & Blue & ++ & + & +++ & + & - & A. parasiticus \\
\hline 08AAsp35 & 500 & $\mathrm{~b}$ & s & $\mathrm{y}$ & 2.7 & - & - & - & - & - & - & A. flavus \\
\hline 08AAsp36 & 1100 & $\mathrm{u} / \mathrm{b}$ & $r$ & d & 0.5 & Blue & ++ & + & +++ & + & - & A. parasiticus \\
\hline 08AAsp37 & 1140 & $\mathrm{~b}$ & S & $\mathrm{y}$ & 2.0 & - & - & - & - & - & - & A. flavus \\
\hline 08AAsp38 & - & $\mathrm{u}$ & $r$ & d & 1.3 & Blue & ++ & + & +++ & + & - & A. parasiticus \\
\hline 08AAsp39 & - & $\mathrm{u}$ & $\mathrm{r}$ & d & 2.2 & Blue & ++ & + & ++ & + & - & A. parasiticus \\
\hline 08AAsp42 & - & $\mathrm{b}$ & s & $\mathrm{y}$ & 2.5 & Violet & + & $+1-$ & - & - & + & A. flavus \\
\hline 08AAsp43 & - & $\mathrm{b}$ & s & $\mathrm{y}$ & 2.1 & - & - & - & - & - & - & A. flavus \\
\hline 08AAsp66 & 630 & $\mathrm{u} / \mathrm{b}$ & $\mathrm{r}$ & d & 0.5 & Blue & ++ & + & +++ & + & - & A. parasiticus \\
\hline 08AAsp67 & - & $\mathrm{b} / \mathrm{u}$ & $r$ & d & 2.2 & Green & + & + & ++ & ++ & - & A. parasiticus \\
\hline 08AAsp68 & - & $\mathrm{u}$ & $r$ & d & 2.6 & Blue & ++ & + & +++ & + & - & A. parasiticus \\
\hline 08AAsp72 & - & $\mathrm{u}$ & $r$ & d & 2.7 & Blue & ++ & + & +++ & + & - & A. parasiticus \\
\hline 08AAsp76 & 1220 & $\mathrm{~b} / \mathrm{u}$ & s & $\mathrm{y}$ & 1.5 & - & - & - & - & - & - & A. flavus \\
\hline 08AAsp77 & - & $\mathrm{b}$ & s & $\mathrm{y}$ & 2.9 & - & - & - & - & - & - & A. flavus \\
\hline 08AAsp83 & 480 & $\mathrm{u}$ & $r$ & d & 1.6 & Blue & ++ & + & +++ & + & - & A. parasiticus \\
\hline 08AAsp101 & - & $\mathrm{u} / \mathrm{b}$ & $r$ & d & 1.6 & Blue & ++ & + & +++ & + & - & A. parasiticus \\
\hline 08AAsp103 & - & $\mathrm{u}$ & $r$ & d & 1.7 & Blue & ++ & + & +++ & + & - & A. parasiticus \\
\hline 08AAsp105 & 970 & $\mathrm{~b} / \mathrm{u}$ & s & $\mathrm{y}$ & 3 & - & - & - & - & - & - & A. flavus \\
\hline 08AAsp108 & - & $\mathrm{u}$ & $r$ & d & 2.8 & Blue & ++ & + & +++ & + & - & A. parasiticus \\
\hline 08AAsp109 & 1070 & $\mathrm{~b}$ & s & $\mathrm{y}$ & 2.7 & - & - & - & - & - & - & A. flavus \\
\hline 08AAsp110 & 660 & $\mathrm{u} / \mathrm{b}$ & $r$ & d & 1.7 & Blue & ++ & + & +++ & + & - & A. parasiticus \\
\hline 08AAsp111 & - & $\mathrm{b} / \mathrm{u}$ & $\mathrm{r}$ & d & 3.1 & Blue & ++ & + & ++ & + & - & A. parasiticus \\
\hline 08AAsp112 & 1070 & $\mathrm{u} / \mathrm{b}$ & S & $\mathrm{y}$ & 2.6 & - & - & - & - & - & - & A. flavus \\
\hline 08AAsp113 & 1430 & $\mathrm{u} / \mathrm{b}$ & s & $\mathrm{y}$ & 2.9 & - & - & - & - & - & - & A. flavus \\
\hline 08AAsp115 & 980 & $\mathrm{~b}$ & $\mathrm{~s}$ & $\mathrm{y}$ & 2.0 & - & - & - & - & - & - & A. flavus \\
\hline 08AAsp116 & - & $\mathrm{b}$ & s & $\mathrm{y}$ & 2.0 & Violet & + & $+1-$ & - & - & + & A. flavus \\
\hline 08AAsp117 & 920 & $\mathrm{u}$ & $r$ & d & 1.8 & Blue & ++ & + & +++ & + & - & A. parasiticus \\
\hline 08AAsp158 & - & $\mathrm{u} / \mathrm{b}$ & $r$ & d & 2.3 & Blue & +++ & ++ & $-1+$ & $-1+$ & - & A. parasiticus \\
\hline \multicolumn{13}{|l|}{ Controls } \\
\hline MUM 92.01 & 440 & $\mathrm{~b} / \mathrm{u}$ & S & $\mathrm{y}$ & 1.8 & Violet & $+1-$ & - & - & - & + & A. flavus \\
\hline MUM 92.02 & 560 & $\mathrm{u}$ & $r$ & d & n.d. & Blue & ++ & ++ & ++ & ++ & - & A. parasiticus \\
\hline 05BrUAs01 & 660 & $\mathrm{~b}$ & s & $\mathrm{y}$ & n.d. & - & - & - & - & - & - & A. flavus \\
\hline 01UAs55 & n.d. & $\mathrm{b}$ & s & $\mathrm{y}$ & n.d. & - & - & - & - & - & - & A. flavus \\
\hline
\end{tabular}

a Size: average of 15 sclerotia; -: absence; n.d.: not determined.

b u: uniseriate; b: biseriate; u/b: predominantly uniseriate; b/u: predominantly biseriate.

c s: smooth; r: rough; fr: finelly rough.

d $\mathrm{y}$ : yellow-green; d: dark-green; $\mathrm{y} / \mathrm{d}$ : in between $\mathrm{y}$ and $\mathrm{d}$.

e Average of 3 colonies, in $\mathrm{cm}$; n.d.: not determined.

f ++: strong signal; +: medium signal; +/-: weak signal; -/+: very weak signal; -: not detected. 
Table 4

Incidence of chemotypes of A. flavus based on mycotoxigenic profile (aflatoxins and CPA)

\begin{tabular}{lllll}
\hline Chemotype & \multicolumn{2}{l}{ Mycotoxins } & & $\begin{array}{l}\text { Number of isolates of } \\
\text { each chemotype (\%) }\end{array}$ \\
\cline { 2 - 4 } & AFB & AFG & CPA & \\
\hline I & + & - & + & $2(15 \%)$ \\
II & + & + & + & $1(8 \%)$ \\
III & + & - & - & $0(0 \%)$ \\
IV & - & - & + & $0(0 \%)$ \\
V & - & - & - & $10(77 \%)$ \\
\hline
\end{tabular}

(After Vaamonde et al., 2003).

weak violet fluorescence on CAM, only detectable after 5 days of incubation. Strain 08AAsp67, the only isolate for which both AFG1 and AFG2 signals were stronger than those for the AFBs on HPLC, showed a green fluorescence on CAM.

All $A$. parasiticus isolates showed a consistent mycotoxigenic profile: they all produced AFB and AFG, and no CPA production was detected. A. flavus isolates were assigned to 3 of the 5 chemotypes proposed by Vaamonde et al. (2003), as shown in Table 4: the vast majority (77\%) were atoxigenic, whereas 2 isolates (15\%) were CPA and AFB producers and one isolate (8\%) produced the 3 groups of mycotoxins. Type-strain MUM 92.01, classified as non-aflatoxigenic, produced residual amounts of AFB1.

Table 5

Presence of genes aflD and aflQ (PCR) and their expression (RT-PCR) in Aspergillus Flavi isolates

\begin{tabular}{|c|c|c|c|c|c|c|}
\hline \multirow[t]{2}{*}{ Isolate code } & \multirow[t]{2}{*}{ Classification } & \multirow[t]{2}{*}{ AFB1 } & \multicolumn{2}{|c|}{$\begin{array}{l}\text { Gene presence } \\
(\mathrm{PCR})\end{array}$} & \multicolumn{2}{|c|}{$\begin{array}{l}\text { Gene expression } \\
\text { (RT-PCR) }\end{array}$} \\
\hline & & & $\overline{a f l D}$ & $\overline{a f l Q}$ & $\overline{a f l D}$ & $\overline{a f l Q}$ \\
\hline 07AAsp05 & A. parasiticus & + & + & + & + & + \\
\hline 07AAsp37 & A. flavus & + & + & + & + & $+/-$ \\
\hline 07AAsp43 & A. parasiticus & + & + & + & + & + \\
\hline 08AAsp34 & A. parasiticus & ++ & + & + & + & + \\
\hline 08AAsp35 & A. flavus & - & - & + & - & - \\
\hline 08AAsp36 & A. parasiticus & ++ & + & + & n.d. & + \\
\hline 08AAsp37 & A. flavus & - & + & + & + & - \\
\hline 08AAsp38 & A. parasiticus & ++ & + & + & + & + \\
\hline 08AAsp39 & A. parasiticus & ++ & + & + & + & + \\
\hline 08AAsp42 & A. flavus & + & + & + & + & - \\
\hline 08AAsp43 & A. flavus & - & + & + & + & - \\
\hline 08AAsp66 & A. parasiticus & ++ & + & + & + & + \\
\hline 08AAsp67 & A. parasiticus & + & + & + & n.d. & $+1-$ \\
\hline 08AAsp68 & A. parasiticus & ++ & + & + & n.d. & + \\
\hline 08AAsp72 & A. parasiticus & ++ & + & + & n.d. & + \\
\hline 08AAsp76 & A. flavus & - & + & + & n.d. & - \\
\hline 08AAsp77 & A. flavus & - & + & + & n.d. & - \\
\hline 08AAsp83 & A. parasiticus & ++ & + & + & n.d. & + \\
\hline 08AAsp101 & A. parasiticus & ++ & + & + & n.d. & + \\
\hline 08AAsp103 & A. parasiticus & ++ & + & + & n.d. & + \\
\hline 08AAsp105 & A. flavus & - & + & + & n.d. & - \\
\hline 08AAsp108 & A. parasiticus & ++ & + & + & n.d. & + \\
\hline 08AAsp109 & A. flavus & - & + & + & n.d. & - \\
\hline 08AAsp110 & A. parasiticus & ++ & + & + & n.d. & + \\
\hline 08AAsp111 & A. parasiticus & ++ & + & + & n.d. & + \\
\hline 08AAsp112 & A. flavus & - & + & + & n.d. & - \\
\hline 08AAsp113 & A. flavus & - & + & + & n.d. & - \\
\hline 08AAsp115 & A. flavus & - & + & + & n.d. & - \\
\hline 08AAsp116 & A. flavus & + & + & + & n.d. & - \\
\hline 08AAsp117 & A. parasiticus & ++ & + & + & n.d. & + \\
\hline 08AAsp158 & A. parasiticus & +++ & + & + & n.d. & + \\
\hline \multicolumn{7}{|l|}{ Controls } \\
\hline MUM 92.01 & A. flavus & $+1-$ & + & + & + & - \\
\hline MUM 92.02 & A. parasiticus & ++ & + & + & + & + \\
\hline 05BrUAs01 & A. flavus & - & - & - & - & - \\
\hline 01UAs55 & A. flavus & - & - & - & - & - \\
\hline
\end{tabular}

n.d. not determined.

+: strong signal; +/-: weak signal; -: no signal detected.

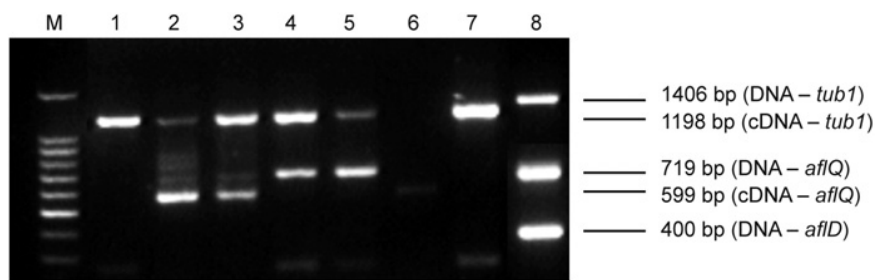

Fig. 1. Agarose gel electrophoretic pattern of reverse transcriptase-PCR products. $M$ molecular weight 100 bp ladder (Promega); 1 - 08AAsp35(-); 2 - 08AAsp36(+); 3 08AAsp72(+); 4 - 08AAsp76(-); 5 - 08AAsp77(-); 6 - 08AAsp83(+); 7 - 05BrUAs01 $(-) ; 8$ - DNA-PCR control

\subsection{Molecular analysis}

PCR and RT-PCR results are presented in Table 5. From field isolates, and considering both genes under study ( $a f l D$ and $a f l Q$ ), only 08AAsp35 (-) was negative for the aflD amplicon, whereas 01UAs55 and 05BrUAs01, herein used as negative controls, showed no amplification for both aflD and aflQ. Gene expression analysis shows a more diverse pattern. All isolates tested for aflD expression gave a positive result, even for atoxigenic isolates. The only exceptions were, as expected, the isolates negative for aflD presence (08AAsp35, 01UAs55 and 05BrUAs01). aflQ expression was tested for all isolates. All strong AFB1 producers showed an amplicon near $600 \mathrm{bp}$, corresponding to the expected aflQ mRNA. This fragment was not detected in atoxigenic isolates. Among the weak producers of AFB1, isolates 07AAsp37 and 08AAsp67 showed a weak expression signal, and isolates 08AAsp42, 08AAsp116 and MUM92.01 showed no signal for aflQ expression. Fig. 1 is representative of the electrophoretic band patterns obtained for both aflatoxigenic and nonaflatoxigenic isolates relative to tub1 and aflQ expression.

\section{Discussion}

In the present study, we aimed to identify and characterize $31 \mathrm{As}$ pergillus isolates belonging to Section Flavi. Morphological differentiation of species belonging to this group is difficult, due not only to interspecific similarities, but also to intraspecific variability. The major morphological characters used for A. flavus and A. parasiticus distinction are colony color and conidia morphology, but sclerotia presence and size as well as conidial head seriation are other characters that can be used to assist identification. Morphological characterization is usually complemented with mycotoxigenic pattern of AFs and CPA production ability. Kurtzman et al. (1987) refer to an extra character capable of distinguishing A. nomius from other related species, which is its limited growth at $42{ }^{\circ} \mathrm{C}$ on $\mathrm{CZ}$.

Kozakiewicz (1989) reported that production of sclerotia is a rare characteristic of A. flavus strains only, and, in accordance to Klich (2007), the presence of sclerotia per se does not seem to be related to aflatoxin production, but the presence of small sclerotia appears to be correlated with high aflatoxin production. Several authors have tried to establish a correlation between sclerotia production ability and aflatoxigenicity, but published data are contradictory. Various studies refer to a positive correlation between high aflatoxin production and presence of small sclerotia (Chang et al., 2001; Cotty, 1989, 1997; Novas and Cabral, 2002; Pildain et al., 2004), whereas others report no correlation between sclerotial production/size and aflatoxigenicity (Giorni et al., 2007; Razzaghi-Abyaneh et al., 2006) or even an inverse correlation, with Ltype strains being the most toxigenic (Abbas et al., 2005). Inconsistency of results may impart from the fact that fungal growth conditions have not been standardized and several culture media have been used for this purpose. In accordance to Cotty (1989), S-type strains usually produce high levels of aflatoxins and numerous sclerotia smaller than $400 \mu \mathrm{m}$ in diameter. One atypical S-type A. flavus producer of AFBs, AFGs and CPA have been raised to species and named $A$. parvisclerotigenus (Frisvad et al., 2005). 
In our study, we have identified both A. parasiticus and A. flavus isolates, aflatoxigenic and non-aflatoxigenic, as sclerotia producers. Among the A. flavus isolates, we could only detect the L-morphology, since they all produced sclerotia bigger than $400 \mu \mathrm{m}$ under the tested conditions. We could not establish a correlation between sclerotia presence/size and toxigenicity. Isolate 07AAsp37, which produces both AFs and CPA did not produce small sclerotia, a condition required to be classified as A. parvisclerotigenus (Frisvad et al., 2005), and it remained with the classification A. flavus.

It has been reported that CAM fluorescence does not always correspond to aflatoxin detection by chromatography (Abarca et al., 1988; Giorni et al., 2007; Scherm et al., 2005). Abarca et al. (1988) report that blue fluorescence on CAM was detected in only 4 out of ten aflatoxigenic A. flavus strains. We found that all isolates producing a strong signal for AFBs on the HPLC chromatogram showed a marked blue fluorescence pattern (all of them $A$. parasiticus), whereas those producing a weak signal on HPLC showed weak violet fluorescence on CAM (all being A. flavus). The only isolate for which the AFGs signal was stronger than that for the AFBs on HPLC, showed a green fluorescence on CAM.

The usually accepted formula is that not all A. flavus isolates produce aflatoxins, and those that do usually produce only AFBs (and CPA), whereas almost all A. parasiticus isolates produce both aflatoxins $B$ and $\mathrm{G}$, but not CPA (Klich, 2007). But numerous studies have shown that the mycotoxigenic potential and profile of $A$. flavus is far more variable. In fact, this species has been frequently divided into groups, depending on their toxigenic profile (Giorni et al., 2007; Razzaghi-Abyaneh et al., 2006; Vaamonde et al., 2003). The incidence of atoxigenic strains of A. flavus has shown to be highly variable with geographic origin (Atehnkeng et al., 2008; Pildain et al., 2004; Razzaghi-Abyaneh et al., 2006) and substrate (Vaamonde et al., 2003).

In the present study, we found a vast majority (77\%) of atoxigenic A. flavus isolates. Aflatoxigenic ability is, in fact, an unstable character in A. flavus, and its adaptation to the carbon-rich environments of certain agricultural commodities may be involved in gene loss responsible for the loss of aflatoxigenicity (Perrone et al., 2007). This could possibly be the case for our substrate.

A. parasiticus strains are, as already mentioned, more uniform in their toxigenic abilities: they are usually reported as strongly aflatoxigenic, and are rarely non-aflatoxigenic (Horn et al., 1996; Razzaghi-Abyaneh et al., 2006; Tran-Dinh et al., 1999; Vaamonde et al., 2003). With the exception of one isolate (08AAsp67), all our A. parasiticus isolates were found to be strongly aflatoxigenic.

Our results are similar to those obtained in a survey in corn field soils in Iran. Razzaghi-Abyaneh et al. (2006) report 100\% aflatoxigenic A. parasiticus isolates and only $27.5 \%$ of aflatoxigenic A. flavus strains.

Although type-strain MUM92.01 (NRRL 6412) is classified as nonaflatoxigenic, we detected a weak AFB1 production ability. In fact, Wicklow et al. (1981) report that single-spore isolates of this strain were either AFB1 producers or non-producers on aflatoxin-production ability (APA) medium, and that it produced substantial amounts of aflatoxin when cultivated on cracked corn. These results provide evidence that strains can be genetically heterogeneous and that in vitro conditions can be misleading.

For the molecular analysis of our isolates, we have selected the aflD gene, which is responsible for the conversion of norsolorinic acid (NOR) to averantin (AVN) in the middle of the aflatoxin biosynthetic pathway (Yu et al., 2004a), because its expression had been reported as showing a high correlation to aflatoxigenic ability (Scherm et al., 2005). The aflQ gene was specifically chosen because it is considered to be the only gene involved in the final step of transforming $O$-methylsterigmatocystin (OMST) into AFB1, a crucial step of the aflatoxin pathway that seems to be unique to aflatoxigenic species (Prieto and Woloshuk, 1997).

As expected, the presence of these two genes could not be correlated to aflatoxin producing ability. Other authors had already tried multiplex PCR, without success (Geisen, 1996).
Scherm et al. (2005) tested 9 structural and 2 regulation genes in 13 lab strains and concluded that aflD expression had the best correlation between aflatoxigenicity and gene expression, and that aflQ expression did not show any consistency. Furthermore, they could not identify aflQ expression in any of the A. flavus strains, only in the aflatoxigenic $A$. parasiticus strains.

Since multiplex RT-PCR for the 3 genes (tub1, aflQ and aflD) revealed some inconsistency in the amplification patterns, we chose to test aflD and aflQ expression separately. We found expression of aflD in both aflatoxigenic and non-aflatoxigenic isolates, and for that reason we chose not to analyse its expression for all the isolates.

In respect to aflD expression, our results are contradictory to those reported by these authors. We could not find any correlation between aflD expression and aflatoxin production.

RT-PCR for aflQ showed a confusing, but consistent, band pattern (Fig. 1). When using the primer pair ord1-gF/ord1-gR proposed by Scherm et al. (2005) for the amplification from RNA, we detected a band corresponding to the size of the expected amplification from DNA (719 bp) in all isolates and another band corresponding to the expected amplification from RNA (599 bp) in the toxigenic isolates. To exclude the possibility of DNA contamination of the RNA, we ran a PCR for the RNA samples and no amplification occurred, confirming the efficacy of the DNase treatment. Furthermore, if any DNA contamination was to be present, two bands for the tub1 gene would appear at sizes 1406 bp (DNA) and 1198 bp (RNA). Only the smaller band was present, further confirming the purity of the RNA samples. The primer pair ord1-gF/ord1-cR proposed by Degola et al. (2007) did not produce any amplicon.

We detected a fragment corresponding to aflQ mRNA (599 bp) in all strong aflatoxigenic isolates, but not in the non-aflatoxigenic nor in the weak AFs producers (all A. flavus). Scherm et al. (2005) were able to detect aflQ expression in A. parasiticus strains only, and not in any of the A. flavus tested, even the aflatoxigenic ones. Our strong aflatoxigenic isolates, which showed a marked aflQ signal, are all classified as $A$. parasiticus. The fact that we were not able to detect aflQ expression in aflatoxigenic A. flavus is in accordance with those authors. It could result from the fact that they are very weak AFs producers, and gene expression is not detected, or because of incompatibility of the primers with A. flavus aflQ mRNA sequence. In fact, Sweeney et al. (2000) tested this primer pair for one strain of $A$. parasiticus only, but the EMBL sequence used for constructing the primers is reported to be the one corresponding to the A. flavus aflQDNA sequence (=ord1, EMBL Accession no. U81806). Primers sequences are in fact present in both A. flavus aflQ DNA and CDNA (EMBL Accession no. U81807), so the non-detection of A. flavus aflQ expression should not be the result of lack of complementarity between mRNA and primers sequences. However, we could detect a weak signal in the weak producer 07AAsp37, classified as A. flavus.

In conclusion, a polyphasic approach consisting of morphological, chemical and molecular characterization was applied to 31 isolates of Aspergillus Section Flavi originating from Portuguese almonds with the aim of characterizing and identifying aflatoxigenic and non-aflatoxigenic strains. Fifty-eight percent were $A$. parasiticus, all being aflatoxin producers, and $42 \%$ A. flavus, of which only $23 \%$ were aflatoxigenic. Mycotoxin production on CAM revealed consistent to HPLC analysis, and we could even differentiate a strong AFGs producer by a green fluorescence on CAM. Molecularly, afID expression was not considered a good marker for differentiating aflatoxigenic from non-aflatoxigenic isolates, but aflQ showed a good correlation between expression and aflatoxin-production ability.

All material having had contact with mycotoxins was considered hazardous waste, and was thus conveniently decontaminated prior to disposal.

\section{Acknowledgment}

P. Rodrigues was supported by the grant SFRH/BD/28332/2006 from Fundação para a Ciência e a Tecnologia (FCT), Portugal. 


\section{References}

Abarca, M.L., Bragulat, M.R., Bruguera, M.T., Cabañes, F.J., 1988. Comparison of some screening methods for aflatoxigenic moulds. Mycopathologia 104, 75-79.

Abbas, H.K., Weaver, M.A., Zablotowicz, R.M., Horn, B.W., Shier, W.T., 2005. Relationships between aflatoxin production and sclerotia formation among isolates of Aspergillus Section Flavi from the Mississippi Delta. European Journal of Plant Pathology 112, 283-287.

Atehnkeng, J., Ojiambo, P.S., Donner, M., Ikotun, T., Sikora, R.A., Cotty, P.J., Bandyopadhyay, R. 2008. Distribution and toxigenicity of Aspergillus species isolated from maize kernels from three agro-ecological zones in Nigeria. International Journal of Food Microbiology $122,74-84$.

Bragulat, M.R., Abarca, M.L., Cabañes, F.J., 2001. An easy screening method for fungi producing ochratoxin A in pure culture. International Journal of Food Microbiology 71, 139-144.

Brown, D.W., Yu, J.H., Kelkar, H.S., Fernandes, M., Nesbitt, T.C., Keller, N.P., Adams, T.H. Leonard, T.J., 1996. Twenty-five coregulated transcripts define a sterigmatocystin gene cluster in Aspergillus nidulans. Proceedings of the National Academy of Sciences of the United States of America 93, 1418-1422.

Cary,J.W., Ehrlich, K.C., 2006. Aflatoxigenicity in Aspergillus: molecular genetics, phylogenetic relationships and evolutionary implications. Mycopathologia 162,167-177.

Chang, P.K., Bennett, J.W., Cotty, P.J., 2001. Association of aflatoxin biosynthesis and sclerotial development in Aspergillus parasiticus. Mycopathologia 153, 41-48.

Cotty, P.J., 1989. Virulence and cultural characteristic of two Aspergillus flavus strains pathogenic on cotton. Phytopathology 79, 808-814.

Cotty, P., 1997. Aflatoxin-producing potential of communities of Aspergillus Section Flavi from cotton producing areas in the United States. Mycological Research 101, 698-704.

Criseo, G., Bagnara, A., Bisignano, G., 2001. Differentiation of aflatoxin-producing and nonproducing strains of Aspergillus flavus group. Letters in Applied Microbiology 33, 291-295.

Davies, N.D., Iyer, S.K., Diener, U.L., 1987. Improved method of screening for aflatoxin with a coconut agar medium. Applied and Environmental Microbiology 53, 1593-1595.

Degola, F., Berni, E., Dall'Asta, C., Spotti, E., Marchelli, R., Ferrero, I., Restivo, F.M., 2007. A multiplex RT-PCR approach to detect aflatoxigenic strains of Aspergillus flavus. Journal of Applied Microbiolgy 103, 409-417.

Detroy, R.W., Freer, S., Ciegler, A., 1973. Aflatoxin and anthraquinone biosynthesis by nitrosoquanidine-derived mutants of Aspergillus parasiticus. Canadian Journal of Microbiology 19, 1373-1378.

Ehrlich, K.C., Chang, P.-K., Yu, J., Cotty, P.J., 2004. Aflatoxin biosynthesis cluster gene cypA is required for $\mathrm{G}$ aflatoxin formation. Applied and Environmental Microbiology 70 6518-6524.

Ehrlich, K.C., Kobbeman, K., Montalbano, B.G., Cotty, P.J., 2007. Aflatoxin-producing Aspergillus species from Thailand. International Journal of Food Microbiology 114, 153-159.

Färber, P., Geisen, R., Holzapfel, W.H., 1997. Detection of aflatoxigenic fungi in figs by a PCR reaction. International Journal of Food Microbiology 36, 215-220.

Fiebelman, T.P., Cotty, P.J., Doster, M.A., Michailides, T.J., 1998. A morphologically distinct strain of Aspergillus nomius. Mycologia 90, 618-623.

Frisvad, J.C., Skouboe, P., Samson, R.A., 2005. Taxonomic comparison of three different groups of aflatoxin producers and a new efficient producer of aflatoxin B1, sterigmatocystin and 3-O-methylsterigmatocystin, Aspergillus rambellii sp. nov. Systematic and Applied Microbiology 28, 442-453.

Geisen, R., 1996. Multiplex polymerase chain reaction for the detection of potential aflatoxin and sterigmatocystin producing fungi. Systematic and Applied Microbiology 19, 388-392.

Giorni, P., Magan, N., Pietri, A., Bertuzzi, T., Battilani, P., 2007. Studies on Aspergillus Section Flavi isolated from maize in northern Italy. International Journal of Food Microbiology 113, 330-338.

Gqaleni, N., Smith, J.E., Lacey, J., Gettinby, G., 1997. Effects of temperature, water activity, and incubation time on production of aflatoxins and cyclopiazonic acid by an isolate of Aspergillus flavus in surface agar culture. Applied and Environmental Microbiology 63, 1048-1053.

Horn, B.W., Greene, R.L, Sobolev, V.S, Dorner, JW. Powell, J.H. 1996. Association of morphology and mycotoxin production with vegetative compatibility groups in Aspergillus flavus, A. parasiticus, and A. tamarii. Mycologia 88, 574-587.
Ito, Y., Peterson, W., Goto, T., 1998. Isolation and characterization of Aspergillus nomius from Japanese soil and silkwarm excrement. Journal of the Japanese Association of Mycotoxicology 46, 9-15 (Abstract)

Klich, M.A., 2002. Identification of Common Aspergillus Species. CBS, Netherlands.

Klich, M.A., 2007. Environmental and developmental factors influencing aflatoxin production by Aspergillus flavus and Aspergillus parasiticus. Mycosience 48, 71-80.

Kozakiewicz, Z., 1989. Aspergillus Species on Stored Products. CAB International.

Kumeda, Y., Asao, T., 2001. Heteroduplex panel analysis, a novel method for genetic identification of Aspergillus Section Flavi strains. Applied and Environmental Microbiology 67, 4084-4090.

Kurtzman, C.P., Horn, B.W., Hesseltine, C.W., 1987. Aspergillus nomius, a new aflatoxinproducing species related to Aspergillus flavus and Aspergillus tamarii. Antonie van Leeuwenhoek 53, 147-158.

Mayer, Z., Bagnara, A., Färber, P., Geisen, R., 2003. Quantification of the copy number of nor-1, a gene of the aflatoxin biosynthetic pathway by real-time PCR, and its correlation to the cfu of Aspergillus flavus in foods. International Journal of Food Microbiology 82, 143-151.

Novas, M.V., Cabral, D., 2002. Association of mycotoxin and sclerotia production with compatibility groups in Aspergillus flavus from peanut in Argentina. Plant Disease $86,215-219$

Paterson, R.P.M., 2006. Identification and quantification of mycotoxigenic fungi by PCR. Process Biochemistry 41, 1467-1474.

Perrone, G., Susca, A., Cozzi, G., Ehrlich, K., Varga, J., Frisvad, J.C., Meijer, M., Noonim, P., Mahakarnchanakul, W., Samson, R.A., 2007. Biodiversity of Aspergillus species in some important agricultural products. Studies in Mycology 59, 53-66.

Pildain, M.B., Vaamonde, G., Cabral, D., 2004. Analysis of population structure of Aspergillus flavus from peanut based on vegetative compatibility, geographic origin, mycotoxin and sclerotia production. International Journal of Food Microbiology 93, $31-40$.

Prieto, R., Woloshuk, C.P., 1997. ord1, an oxidoreductase gene responsible for convertion of $\mathrm{O}$-methylsterigmatocystin to aflatoxin in Aspergillus flavus. Applied and Environmental Microbiology 63, 1661-1666.

Razzaghi-Abyaneh, M., Shams-Ghahfarokhi, M., Allameh, A., Kazeroon-Shiri, A., RanjbarBahadori, S., Mirzahoseini, H., Rezaee, M.-B., 2006. A survey on distribution of Aspergillus Section Flavi in corn field soils in Iran: population patterns based on aflatoxins, cyclopiazonic acid and sclerotia production. Mycopathologia 161, 183-192.

Samson, R.A., Hoekstra, E.S., Frisvad, J.C., 2004. Introduction to Food- and Airborne Fungi, 7th ed. CBS, Wageningen.

Scherm, B., Palomba, M., Serra, D., Marcello, A., Migheli, Q., 2005. Detection of transcripts of the aflatoxin genes aflD, aflO, and aflP by reverse-transcription-polymerase chain reaction allows differentiation of aflatoxin-producing isolates of Aspergillus flavus and Aspergillus parasiticus. International Journal of Food Microbiology 98, 201-210.

Shapira, R. Paster, N., Eyal, O., Menasherov, M., Mett, A., Salomon, R., 1996. Detection of aflatoxigenic molds in grains by PCR. Applied and Environmental Microbiology 62, 3270-3273.

Somashekar, D., Rati, E.R., Anand, S., Chandrashekar, A., 2004. Isolation, enumeration and PCR characterization of aflatoxigenic fungi from food and feed samples in India. Food Microbiology 21, 809-813.

Sweeney, M.J., Pàmies, P., Dobson, A.D.W., 2000. The use of reverse transcriptionpolymerase chain reaction (RT-PCR) for monitoring aflatoxin production in Aspergillus parasiticus 439. International Journal of Food Microbiology 56, 97-103.

Tran-Dinh, N., Pitt, J.I., Carter, D.A., 1999. Molecular genotype analysis of natural toxigenic and nontoxigenic isolates of Aspergillus flavus and A. parasiticus. Mycological Research 103, 1485-1490.

Vaamonde, G., Patriarca, A., Pinto, V.F., Comeria, R., Degrossi, C., 2003. Variability of aflatoxin and cyclopiazonic acid production by Aspergillus Section Flavi from different substrates in Argentina. International Journal of Food Microbiology 88, 79-84.

Wei, D., Jong, S., 1986. Production of aflatoxins by strains of the Aspergillus flavus group maintained in ATCC. Mycopathologia 93, 19-24.

Wicklow, D.T., Shotwell, O.L., Adams, G.L., 1981. Use of aflatoxin producing ability medium to distinguish aflatoxin producing strains of Aspergillus flavus. Applied and Environmental Microbiology 41, 697-699.

Yu, J., Bhatnagar, D., Cleveland, T.E., 2004a. Completed sequence of aflatoxin pathway gene cluster in Aspergillus parasiticus. FEBS Letters 564, 126-130.

Yu, J., Chang, P.-K., Ehrlich, K.C., Cary, J.W., Bhatnagar, D., 2004b. Clustered pathway genes in aflatoxin biosynthesis. Applied and Environmental Microbiology 70, 1253-1262. 